drought in recent years. With strongly expressed cautionary statements as to the insecurity of such predictions, I have given him, year by year, the following indications.

1934: "There will be more precipitation in Minnesota and the Dakotas in 1934 than in 1933, but it will be in the latter half of 1934 that the relief will come."'

1935 : "One could hardly expect normal rainfall in South Dakota in 1935."

1936 : "Precipitation far below normal, but with some improvement in the autumn. As regards temperature, the year 1935 followed almost exactly the pattern of temperature 46 years ago, i.e., 1889 . If 1936 should follow 1890, it should show a very cold winter (as indeed has occurred), followed by normal temperature in spring and the early part of the summer."

1937 : "A good precipitation in the spring or early summer of 1937, followed by a dry autumn and winter, recovery in the spring of 1938."
1938 : "Normal precipitation during the first six months of 1938 , with some (but not excessive) letdown for the remainder of the year, and for the first five months of 1939. Then a short dry spell in the middle of 1939 , but precipitation normal or above normal after November 1939 for considerable time."

In January 1938, my correspondent said : "Because of the accuracy of your former predictions of weather conditions for the Dakotas, I am again soliciting your predictions for the coming season. I have much confidence in your ability to predict, therefore please do your best once more."

These forecasts were made by studying the departures from normal conditions at Bismarck, North Dakota, 46 years previously. How well they were fulfilled is to be estimated by examining the accompanying graph.

\title{
Use of Isotopes in Biology
}

$\mathrm{T}^{\mathrm{H}}$ HE discovery both of artificial radioactive elements and heavy non-radioactive isotopes, together with methods of concentration of the latter, has opened up new methods of examining the reactions and movements of substances in the body.

The isotopic indicator most frequently used in biological research is radioactive phosphorus $\left({ }^{32} \mathrm{P}\right)$ which may be prepared by the bombardment of carbon disulphide by neutrons from a radiumberyllium source. The sulphur atom takes up a neutron and gives out a proton, forming heavy, unstable, radioactive phosphorus (half-life period 14 days) :

$$
{ }_{16}^{32} \mathrm{~S}+{ }_{0}^{1} n \rightarrow{ }_{15}^{32} \mathrm{P}+{ }_{1}^{1} \mathrm{H} \text {. }
$$

The phosphorus is then oxidized to phosphate. Stronger preparations may be obtained by bombarding red phosphorus with deuterium ions using a cyclotron :

$$
{ }_{15}^{31} \mathrm{P}+{ }_{1}^{2} \mathrm{D} \rightarrow{ }_{15}^{32} \mathrm{P}+{ }_{1}^{1} \mathrm{H} .
$$

For use, a small amount of the labelled sodium phosphate is added to ordinary sodium phosphate solution, and by this means the path of the phosphorus in the body can be traced. Estimations are carried out by observing the decay, at a given time, using a Geiger counter, and comparing directly with the decay of a similar standard at the same time, thus avoiding corrections for the rate of decay due to lapse of time. Thus if it is desired to determine the radioactive phosphorus content of the bone of an animal to which a labelled phosphate solution has been administered (and hence determine any exchange in the phosphate of the bone), a known weight of bone ash from the animal is placed under the Geiger counter and the strength observed. This is compared directly with the same weight of calcium phosphate, precipitated together with the labelled phosphate from a known weight of solution. This method has placed an extremely delicate method of estimation in the hands of the experimenter and has the great advantage that it is not necessary to purify the substance carefully from nonradioactive elements.

of the non-radioactive elements, deuterium $\left({ }^{2} \mathrm{H}\right)$ has been isolated in a state of purity; while heavy oxygen $\left({ }^{18} \mathrm{O}\right)$ and heavy nitrogen $\left({ }^{15} \mathrm{~N}\right)$ have been concentrated sufficiently to make their use as indicators possible.

Heavy hydrogen and oxygen may be accurately estimated by conversion to water, and, after careful purification, determination of the density of the latter. Heavy nitrogen is determined by the mass-spectrograph. This method may also be used for the determination of heavy oxygen: it has the advantage that very careful purification is unnecessary.

It may be objected that the use of isotopes as indicators in the living body may disturb the normal conditions. Actually, the proportion of radioactive phosphorus which it is necessary to use is extremely small, and the radiation from it may be comparable with that from the potassium which is already present in the body, and on decaying it is converted to a sulphur atom. Heavy 
non-radioactive isotopes are also already present in small proportions in the body, and the use of a slightly greater concentration as an indicator should not be objectionable. In the case of deuterium, it may be best to avoid the use of concentrated preparations.

A joint meeting of the Chemical Society and the Physiological Society on February 9 last took the form of a discussion on the use of isotopes in biology, which was opened by Prof. G. von Hevesy, of the Institute of Theoretical Physics, Copenhagen.

Among examples of the use of radioactive phosphorus, Prof. Hevesy described the results of experiments in which labelled sodium phosphate was injected intravenously; blood samples of known volume taken at intervals showed a very rapid decrease at first, followed by a slow decrease, in the labelled phosphate. This was found to be taken up by the bones and organs of the body, but chiefly by the former. It can be shown, by shaking up solid calcium phosphate with labelled phosphate solution, that there is a rapid exchange between the phosphate ions and the phosphate in the solid, the rate depending on the concentrations of the ions and the surface area of the solid. In the case of the body, the weight of the solid phosphate in the bones is very great compared with the inorganic phosphate in the blood, and most of the labelled phosphate will exchange with ordinary phosphate on the surface of the bones. As phosphate is lost by excretion through the kidneys and bowels, the uptake of labelled phosphate by the bones will cease, and finally, when the labelled phosphate in the blood is nearly removed, there will be a slow exchange of labelled phosphate back from the bones to the blood. Thus it may be possible to detect labelled phosphate several weeks after administration. Examination of the separate organs of the body enables the passage of the phosphate to be followed, and similarly examination of sections of bone shows that the rate of exchange of phosphate varies with different bones. In the case of growing bone such as the teeth of rats, the greater activity is found in the tooth formed after the addition of the labelled phosphate; the part formed before the addition, however, also shows some activity, indicating that exchange of phosphate takes place at the same time as new growth.

Phosphorus atoms in an organic molecule such as lecithin do not exchange with labelled sodium phosphate. Thus, if active lecithin is found, it indicates that the lecithin molecule has been synthesized after the administration of the labelled sodium phosphate (in the presence of suitable enzymes) and thus a distinction can be made between old and new molecules. This method may be used, for example, to find the place of formation of the phosphatides in the yolk of hens' eggs. By killing a hen five hours after an injection of labelled phosphate, it was found that the liver and plasma phosphatide were very active (the former more than the latter) compared with that in the ovary and yolk; thus the phosphatide molecules formed during the last five hours do not originate in the ovary, but are taken by the ovary from the plasma and used in the building up of the yolk. It was also found that after the egg had left the ovary no labelled phosphatide was formed in it. This was shown by examination of eggs laid less than 20 hours after administration of labelled phosphate (the egg, after leaving the ovary, remains in the oviduct about 20 hours).

The use of radioactive sodium phosphate has also been of great help in a study of the formation of (goat) milk. Samples of blood and milk taken at intervals after administration of labelled phosphate were examined for the activity of the phosphate in the blood and the various phosphorus compounds in the milk. It was found that after three to four hours the milk inorganic phosphate was replaced by the active phosphate of the plasma; while if heavy water was injected at the same time as the active phosphate, after one hour water samples prepared from blood and milk had the same density, the difference in the rates being due to the fact that water molecules diffuse through the membranes at a greater rate than phosphate ions. From the rate at which the casein phosphorus becomes active, compared with the active inorganic phosphorus in the milk, it was estimated that the time of formation of casein in the gland cells was about one hour.

The fact that a few hours after addition of the labelled phosphate the milk phosphatides are only slightly active compared with the inorganic phosphate, indicates that the latter cannot be produced from the former, thus contradicting the view that the fats and inorganic phosphate are produced by the breaking up, in the milk gland, of the phosphatides of the blood. The investigation of problems of milk secretion was also referred to by Dr. S. K. Kon.

Labelled sodium phosphate has also been used in a study of the movements of phosphate in plants. Maize and sunflowers grown first in a culture solution were then transferred to a second solution containing labelled phosphate. The leaves which grew while the plant was in the second solution were examined for activity and compared with the leaves which grew in the first (inactive) solution. It was found that, after four days, the lower leaves had 80 per cent of the activity of the upper leaves, showing that a rapid replacement of phosphate took place. Similar experiments have been carried out using heavy nitrogen as indicator. 
The use of deuterium as an indicator was discussed by Prof. H. S. Raper and Dr. W. E. van Heyningen. The former referred to the work of Cavanagh and Raper, in which fats labelled with deuterium were fed to animals and a study made of the rate of formation of the deuterium labelled lipins in the liver and kidney; the latter gave an account of the work of Schoenheimer and Rittenberg et al. on deuterium as an indicator in the study of intermediary metabolism, and referred especially to the uses and limitations of the method.

The use of heavy oxygen as an indicator was discussed by Dr. J. N. E. Day. He referred to the work of Aten and Hevesy, who examined the possibility of exchange of oxygen in sulphate, with other oxygen atoms present in the body, by injecting heavy sodium sulphate into rabbits, and concluded that there was little or no exchange. Reference was also made to the work of Day and Sheel on the use of heavy oxygen in animal respiration, in which the heaviness of the expired carbon dioxide was determined.

Radioactive sodium was dealt with by Dr. B. G. Maegraith, who mentioned experiments in which active sodium chloride had been injected into rabbits, and the distribution of the active sodium investigated. He suggested that this might be used to estimate the extracellular fluid content of the rabbit.

Dr. W. D. Armstrong described experiments dealing with the exchange of phosphorus of the enamel of teeth and the blood using radioactive phosphorus. A very slow exchange was noticed, indicating, not the formation of new molecules, but exchange of phosphate between enamel and blood. Mr. C. H. Collie referred to work of Collie and Morgan showing that radioactive sulphur can be used as an indicator.

Dr. D. Roaf described a method of producing radioactive phosphorus by irradiation of tricresyl phosphate with slow neutrons.

\section{Obituary Notices}

\section{Prof. Franz Werner}

Pro ROF. FRANZ WERNER'S death, which took place in Vienna on February 18 after a short illness at the age of seventy-two years, came as a shock to his numerous herpetological friends and colleagues the world over. Born in 1867, Franz obtained his doctorate at the University of Vienna in 1890 at the early age of twenty-three years, was appointed assistant in the First Zoological Institute of the University, later rising to be professor there, and had a distinguished record as a teacher until 1933, when he became emeritus professor. For more than fifty years, almost up to his death, he was zealously engaged in zoological researches, being in the foremost ranks of European herpetologists and a recipient of many honours. He was a corresponding member of the Vienna Academy of Sciences, an honorary doctor of the University of Athens, an honorary member of the American Society of Ichthyologists and Herpetologists, and a member of numerous other scientific societies.

Prof. Werner was a prolific writer, having more than a hundred papers, including some voluminous works, to his credit, the list including not only papers on Amphibia and Reptilia, in which he was principally interested, but also titles on Orthoptera and scorpions. Interested at first in morphological problems, he became more and more devoted to faunal exploration and herpetological taxonomy as the years went by. He undertook many travels for the sake of such study, and made valuable contributions to our knowledge of the fauna of Greece and the Egean Islands (1902, 1912, 1927, 1930, 1933, 1935, 1936, 1937), Algeria and Morocco (1914, 1929, 1931), Asia Minor
(1902, 1903, 1905, 1929), Persia (1903, 1917, 1929, 1936), South and West Africa (1902, 1913, 1915), Anglo-Egyptian Sudan (1914, 1919, 1924), Guatemala (1903), the Andes (1916), China (1903, 1924), etc. His contributions on Chamæleontidæ (1911), Eublepharidæ, Uroplatidæ, Pygopodidæ (1912) and Reptilia Loricata (1933) in "Das Tierreich" ; on Amphibia and Reptilia in Brehm's "Tierleben" (1913); and on Amphibia (excluding Anura) in Kükenthal's "Handbuch der Zoologie" (1930-31) are models of deep learning and lucid expression, and will make him familiar to younger generations of herpetologists even when the charm of his personality is long forgotten.

He was a patient, enthusiastic and indefatigable worker for herpetology.

\section{B. C. MAHENDRA.}

\section{Dr. E. H. Hankin}

The death on March 29 of Ernest Hanbury Hankin at the age of seventy-four years removes one who in the early days of the development of bacteriology did much to forward its practical applications. The son of a clergyman, he was educated at Merchant Taylors' School, at University College, London, and at St. John's College, Cambridge, of which he was a scholar and later a fellow, obtaining the M.A. and Sc.D. degrees. He also studied at St. Bartholomew's Hospital for a time, but did not proceed to a medical qualification, and worked in Koch's laboratory in Berlin and in the Pasteur Institute, Paris. He then accepted an appointment as chemical examiner, analyst and bacteriologist to the North-West Provinces and Oudh, India, and spent his professional 